\title{
Regulating the Platform Economy: How to Protect Workers While Promoting Innovation
}

The rise of the platform economy has made it a topic of great interest among European policymakers, as evidenced by the European Commission's 2016 Communication "A European agenda for the collaborative economy". The regulatory challenges facing policymakers are manifold, ranging from taxation to competition policy to worker protection. Furthermore, many basic aspects of the platform economy are unclear, such as its size, the number of workers who take part in it and, indeed, its very definition. What types of regulation are necessary to ensure that the benefits of the platform economy are maximised for all Europeans? How can the productivity gains associated with the platform economy be distributed throughout society? Perhaps most importantly, how can policymakers support innovation while also protecting consumers, workers and communities?

Intelligent Tools and Digital Platforms: Implications for Work and Employment

John Zysman, University of California, Berkeley, USA; Berkeley Roundtable on the International Economy, USA.

Martin Kenney, University of California, Davis, USA; Berkeley Roundtable on the International Economy, USA.

Work in the Platform Economy: Beyond Lower Transaction Costs

Jan Drahokoupil, European Trade Union Institute, Brussels, Belgium.

Agnieszka Piasna, European Trade Union Institute, Brussels, Belgium.

Collaborative Economy: Market Design and Basic Regulatory Principles

Georgios Petropoulos, Bruegel, Brussels, Belgium.

The Impact of the Platform Economy on Job Creation

Willem Pieter De Groen, Centre for European Policy Studies, Brussels, Belgium.

Zachary Kilhoffer, Centre for European Policy Studies, Brussels, Belgium.

Karolien Lenaerts, Centre for European Policy Studies, Brussels, Belgium.

Nicolas Salez, Centre for European Policy Studies, Brussels, Belgium. 